\title{
EMBRIO NASIONALISME DALAM BAHASA DAN SASTRA
}

Preprint · August 2019

DOI: $10.13140 /$ RG.2.2.33020.36487

CITATIONS

0

1 author:

Susiati Susiati

Universitas iqra buru

42 PUBLICATIONS 151 CITATIONS

SEE PROFILE

Some of the authors of this publication are also working on these related projects:

Linguist View project

Project Kesantunan Imperatif Bahasa Melayu Ambon View project 
frouplisti
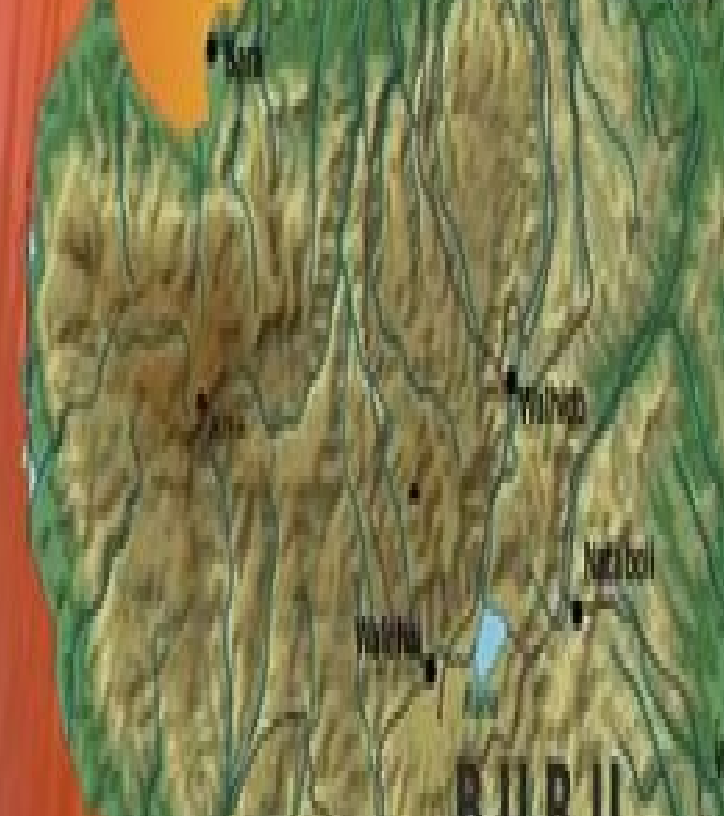
ifyphand

\section{EMBRIO NASIONALISME DALAM BAHASA DAN SASTRA}

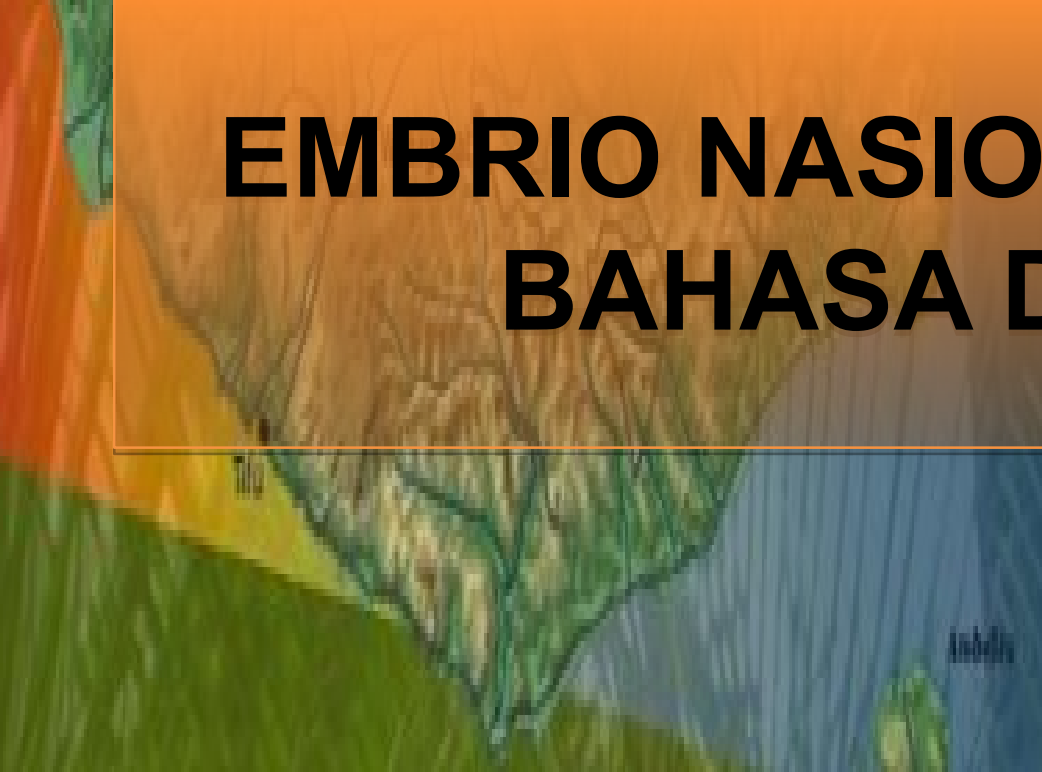

\section{SUSIATI, M.Hum}




\section{BAHASA DAN SASTRA INDONESIA}

\section{PEMBENTUK JATI DIRI KEINDONESIAAN}




\title{
SIKAP TRIGATRA BANGUN BAHASA
}

\author{
UTAMAKAN BAHASA INDONESIA \\ LESTARIKAN BAHASA DAERAH \\ KUASAI BAHASA ASING
}


Jayakan lanskap BI di ruang publik

UTAMAKAN BAHASA INDONESIA

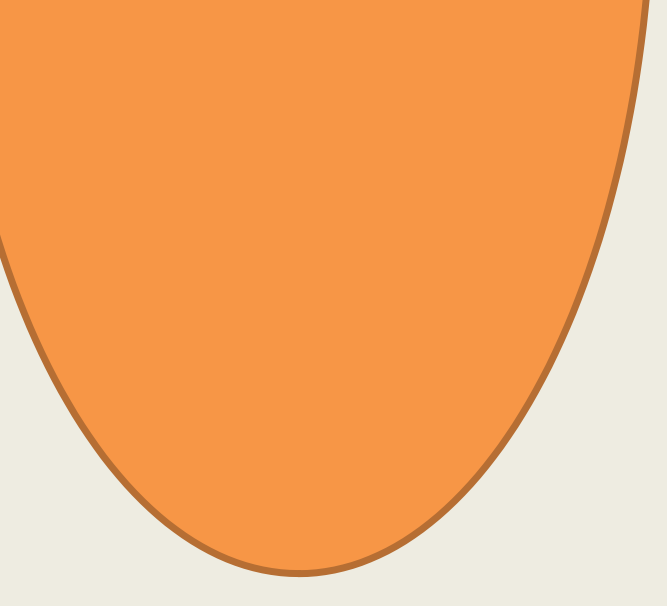

Pengembangan sikap kesantunan berbahasa bagi seluruh lapisan msyarakat khusunya tokoh publik

Penegakan peraturan kebahasaan sebagai upaya untuk mengendalikan penggunaan bahasa di ruang publik

Pemakaian bahasa Indonesia yang baik dan benar 


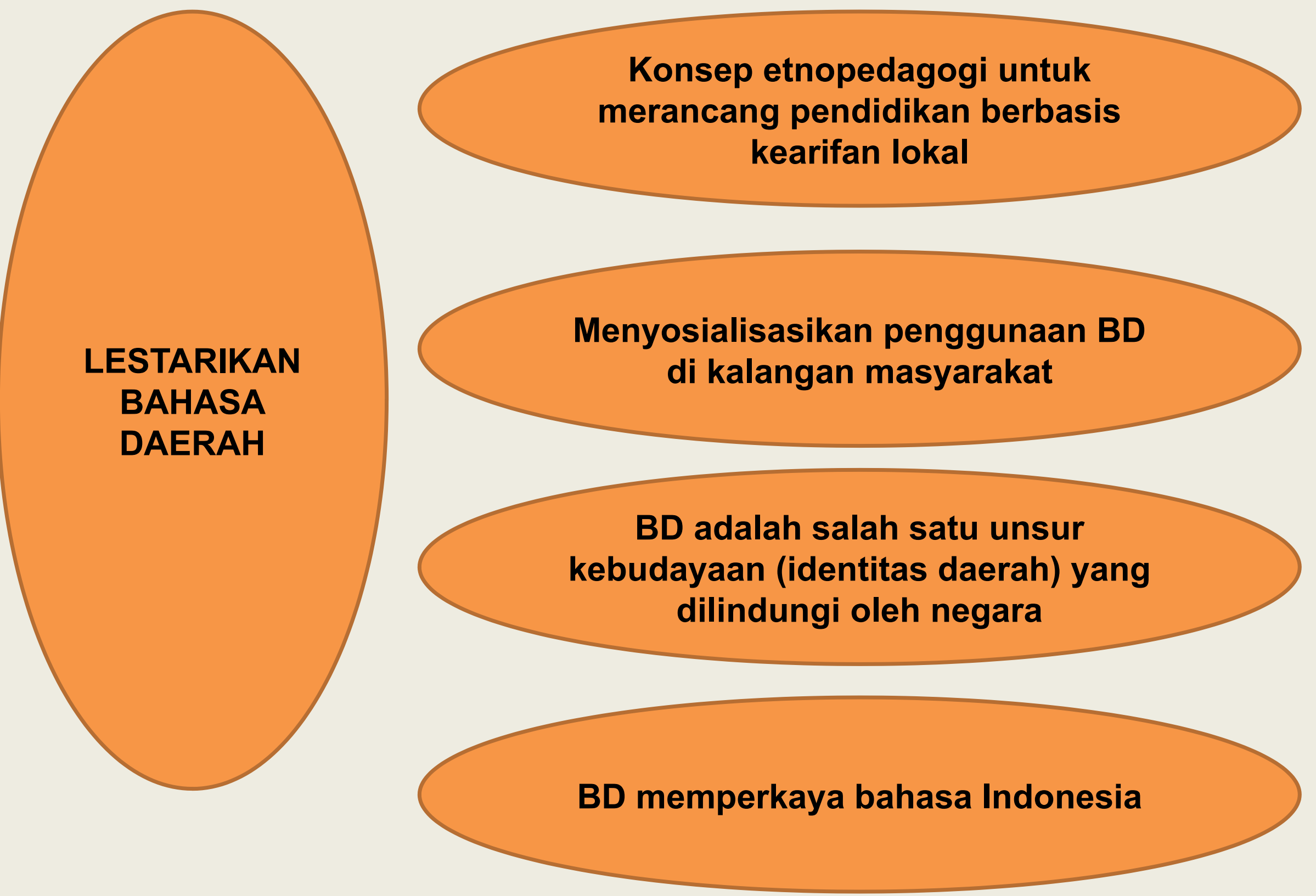




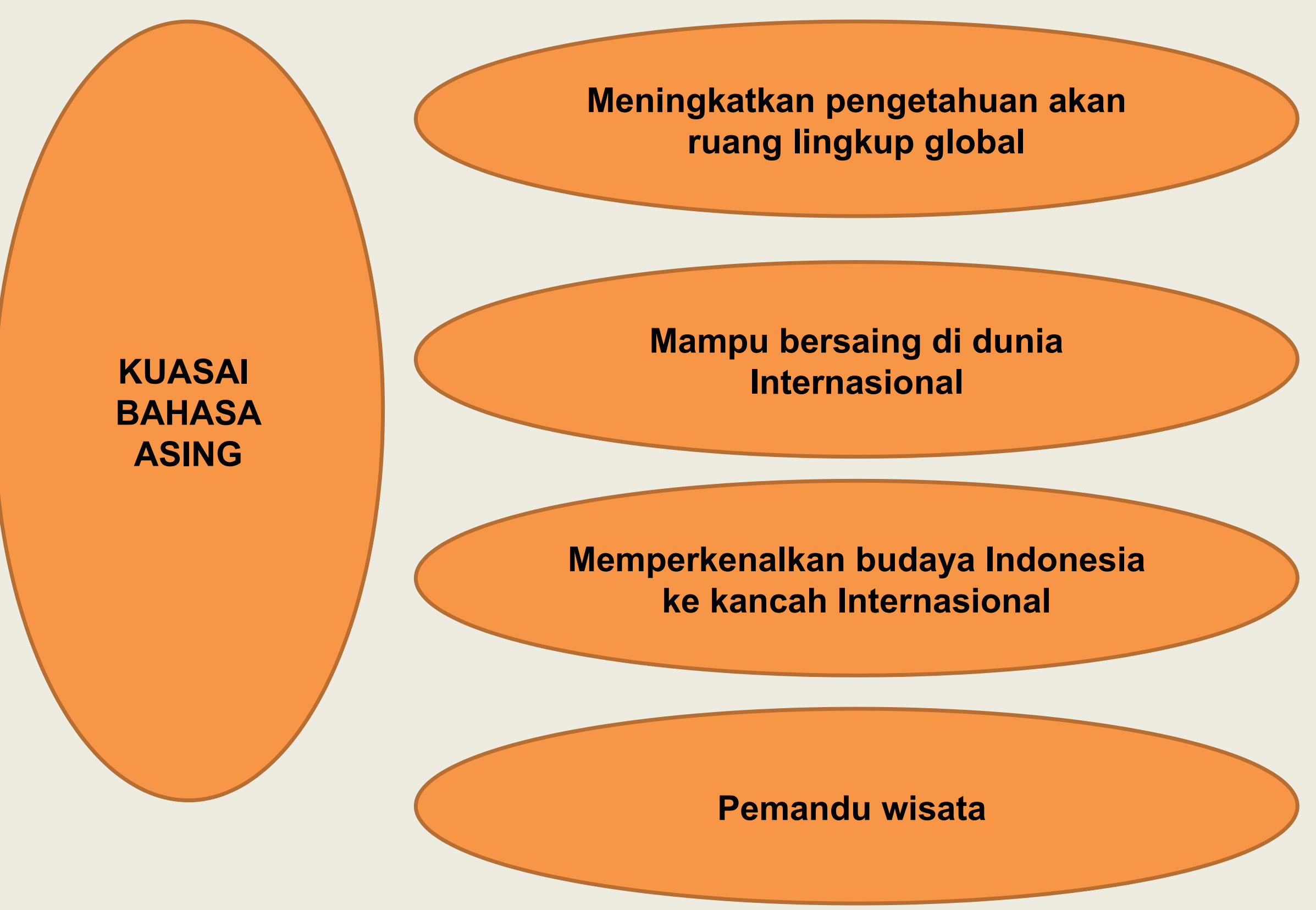




\title{
FUNGSI SASTRA MENDORONG PEMBANGUNAN NASIONAL
}

\author{
SASTRA LISAN
} MANUSKRIP

FILOLOGI 


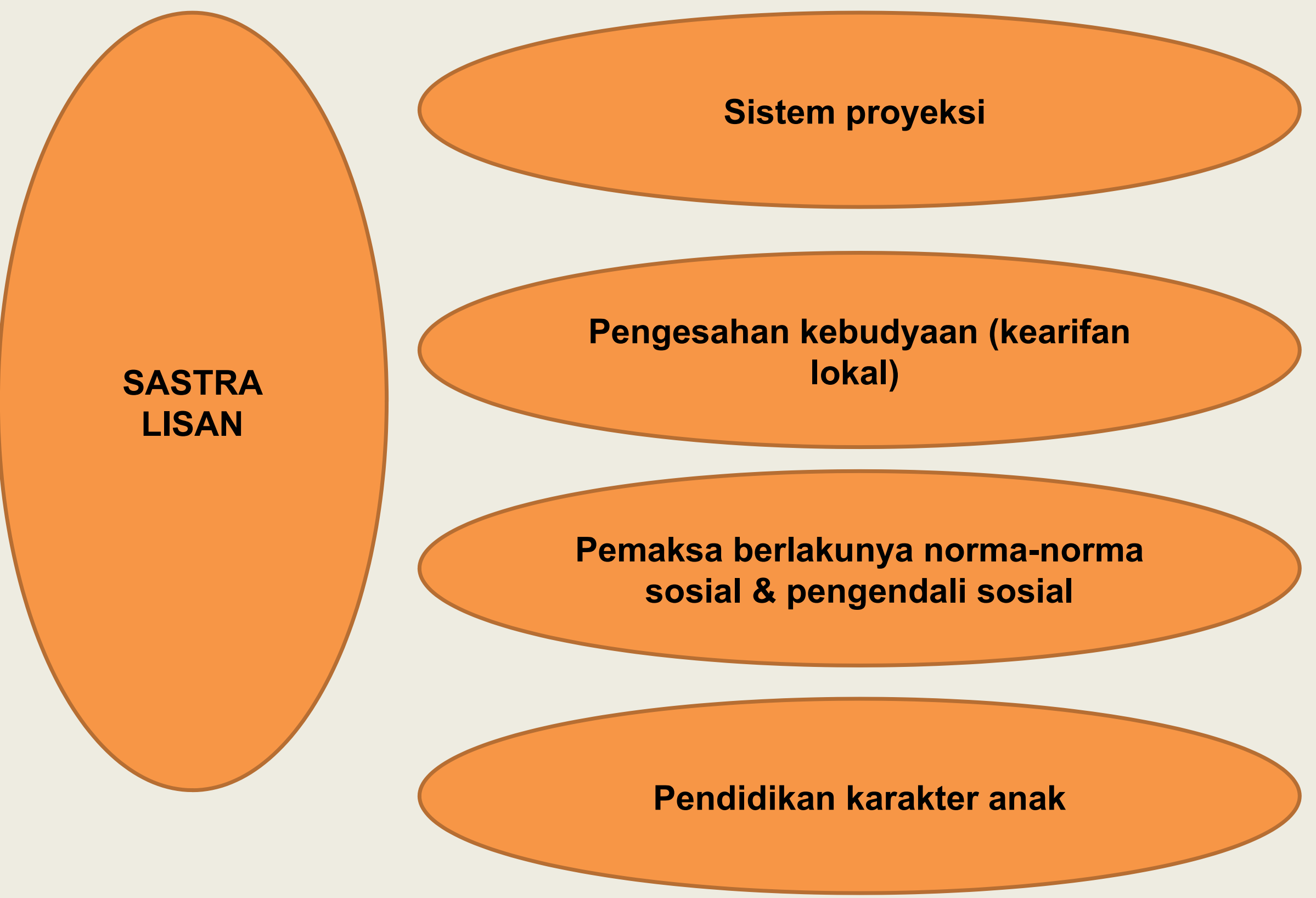




\section{Merevitalisasi kearifan lokal}

\section{Bahan literasi untuk para generasi}

\section{Wadah Pendidikan karakter}

masyarakat 


\section{Mengetahui dan memahami unsur-}

unsur kebudayaan

FILOLOGI

Pelestarian naskah dan teks tentang unsur-unsur budaya masa lampau

Sarana pengembangan kebudayaan 


\section{PERUMUSAN}

- Menjayakan BI di ruang publik

- Pengembangan etnowisata dalam ruang budaya

Penerapan BD sebagai etnopedagogi dalam pendidikan

- Pemanfaatan putra daerah dalam berbahasa asing demi kemajuan wisata 


\section{DAFTAR PUSTAKA}

Iye, R., \& Susiati, S. (2018). NILAI EDUKATIF DALAM NOVEL SEBAIT CINTA DI BAWAH LANGIT KAIRO KARYA MAHMUD JAUHARI ALI (Educative Values in Sebait Cinta di Bawah Langit Kairo by Mahmud Jauhari Ali). Sirok Bastra, 6 (2), 185-191.

RUSDI, M., \& RUSDI, M. (2017). Dinamika Sosial Masyarakat Di Sekiat Bukit Karampuang Desa Barugae Kecamatan Bulukumpa Kabupaten Bulukumba (Doctoral dissertation, Pascasarjana).

Bin-Tahir, S. Z., Atmowardoyo, H., Dollah, S., Rinantanti, Y., \& Suriaman, A. (2018). MULTILINGUAL AND MONO-MULTILINGUAL STUDENTS'PERFORMANCE IN ENGLISH SPEAKING. Journal of Advanced English Studies, 1(2), 32-38.

Susiati, S. (2018). Homonim bahasa kepulauan tukang besi dialek kaledupa di kabupaten wakatobi [the homonymon of tukang besi island languange in kaledupa dialect at wakatobi regency]. Totobuang, 6 (1), 109, 123.

Susiati, S., \& Iye, R. (2018). Kajian Geografi Bahasa dan Dialek di Sulawesi Tenggara: Analisis Dialektometri. Gramatika: Jurnal Ilmiah Kebahasaan dan Kesastraan, 6(2), 137-151.

Susiati, S., Iye, R., \& Suherman, L. O. A. (2019). Hot Potatoes Multimedia Applications in Evaluation of Indonesian Learning In SMP Students in Buru District. ELS Journal on Interdisciplinary Studies in Humanities, 2(4), 556-570. 